\title{
A New Switch and Crossing Design: Introducing the Back to Back Bistable Switch
}

\author{
J. -Y. Shih*, R. Ambur, H. C. Boghani, R. Dixon, E. Stewart \\ Birmingham Centre for Railway Research and Education, University of Birmingham, Birmingham, B15 2TT, UK \\ E-mail: j.shih@bham.ac.uk
}

Received: 29 June 2020; Accepted: 28 July 2020; Available online: 15 August 2020

\begin{abstract}
A new track swtich and crossing (S\&C), the back to back bistable (B2B) switch, is proposed that has shown potential to significantly reduce the wheel/rail contact forces through the switch due to its more continuous wheel/rail contact interface and more uniform track stiffness arising from the elimination of the crossing nose. This offers a major reduction on maintenance cost of future S\&Cs. The paper explains the concept and identifies the design guidelines for a current layout and uses vehicle/turnout dynamic modelling to predict wheel rail forces through a switch to identify performance improvements relative to a conventional S\&C. Both multi-body simulation (MBS) and Finite Element (FE) model have been developed to account for dynamic and thermal analysis. The new design has shown improvements in lateral and vertical wheel-rail contact forces and less relative rail displacements due to thermal effect compared to the conventional S\&C.
\end{abstract}

Keywords: Switch and crossing (S\&C); Wheel/rail contact force; Thermal analysis; Railway; Multi-body simulation (MBS); Finite Element (FE).

\section{Introduction}

Switch maintenance costs account for around $25 \%$ to $30 \%$ of the total maintenance and renewal budget in the UK each year [1,2]. In order to improve this, a better understanding of the dynamic behaviour of S\&C is required. A Multi-body System (MBS) approach, considering variation in rail profiles, is commonly used to investigate the dynamic behaviour of a turnout while a train is passing [3-5]. However, the accuracy of this approach is limited to the lower frequencies [6] with poor prediction of the higher frequency content which usually arises from wheel/rail contact, especially at the crossing nose. Although co-running track model can be implanted to account for higher frequency, the track model needs to be tuned carefully to capture the correct track dynamics [7]. It is easy for plain track; however, it is more complex for S\&C due to non-uniform rail section and bending stiffness.

A simplified Finite Element (FE) turnout models, using beam elements for the rails and springs and dashpots for support stiffness and damping, are used. These take into account the wheel and rail profiles and vehicle/track interactions, and good agreement with site measurements has been shown [6,8,9]. A more detailed contact model has also been considered in order to more accurately calculate the contact patch and pressure in order to make S\&C damage predictions [10]. Additionally, a fully three-dimensional (3D) FE turnout model was developed in order to investigate the influence of different stress type and stress directions for use in the prediction of fatigue life for crossing [11] and bearer failures [12].

Recently some literature have proposed better designs for S\&C in terms of track geometry, rail profile, or support stiffness based on wear and rolling contact fatigue (RCF) analysis [13-15]. However, control of these parameters is not an easy task, and is one which requires a more complex manufacture and installation strategy. Furthermore, one of the common fault, incorrect position of the switch blade, which is usually caused by a failed or failing actuating and locking system, cannot easily be improved based on the existing switch design.

Although a new design of supplementary drive rod and stretcher bar may improve the existing actuating and locking system, it cannot improve the dynamic behaviour of the whole turnout system [16]. More radical approaches are also being proposed such as Repoint [17] and winterproof turnout [18] but has the advantage of redesigning the S\&C together, which is bad for maintenance point of view.

Therefore, a radical design, the back to back bistable (B2B) switch is proposed here. This solution provides a smoother wheel/rail contact interface, passive locking, and high levels of fault tolerance in the actuation and control systems. 


\section{Back to back bistable (B2B) switch}

The back to back bistable (B2B) switch, as shown in Figure 1, was inspired by the REPOINT track switch concept which comprises of a bank of in-bearer type electro-mechanical actuators and a passive locking system using an expansion joint (Figure 2(b)). The system uses multiple channels for actuation, locking and detection, to provide a high degree of fault tolerance [17]. However, where the REPOINT system actuates one end to match the diverging or straight route, the B2B switch includes actuation at both ends of the rails, Zone I and Zone II in Figure 1 to provide a smoother rail profile. The expansion joints have overlapping rails which allow the rail to lengthen or shorten in response to longitudinal movement and to prevent thermal expansion force from reaching the points.

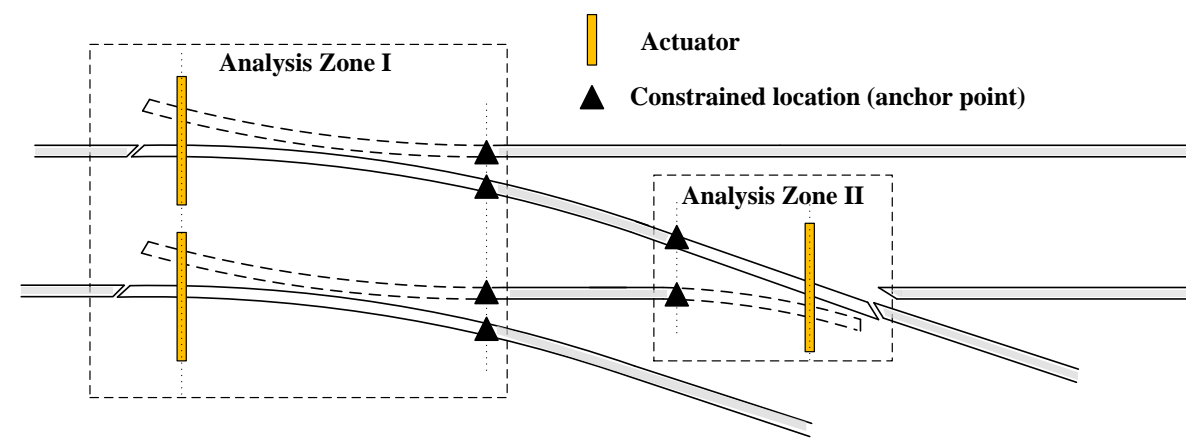

Figure 1. Back to Back Bistable (B2B) Switch

Existing conventional switch designs generally actuator using a single motor to apply forces in order to move the switch blades laterally from one position to another. In contrast, the B2B switch requires the switch blades to be lifted from their current position and dropped into a final position in order to guide the direction of the train. Since the switch blades are lifted against the force of gravity, they must come down again once the lifting force is removed. Hence, the switches have a bistable position where they come to rest in either end position but cannot stay anywhere between them.

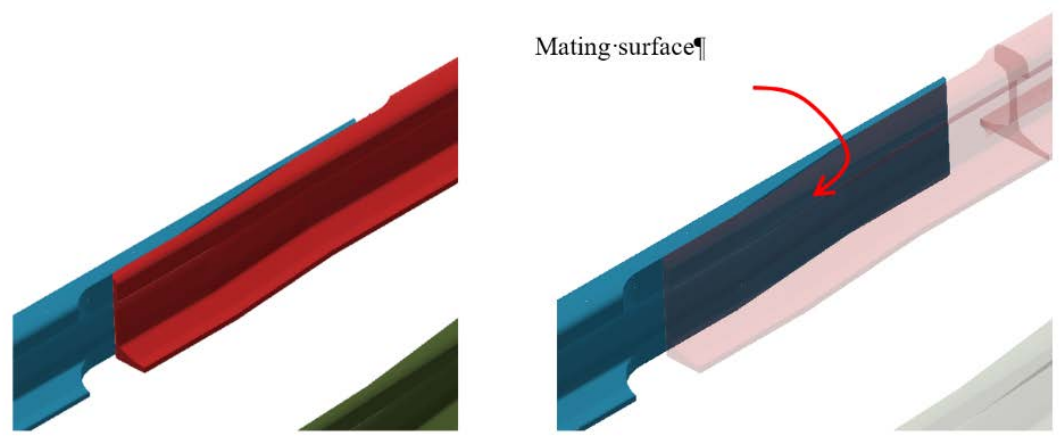

Figure 2. Expansion joint designs from conventional track.

Due to the elimination of the switch blade and crossing nose, which usually cause level and transversal irregularities in the running direction, impact forces transferring through the substructure are reduced. Furthermore, more uniform support and bending stiffnesses are obtained in the crossing region compared to a conventional crossing. This is a crucial factor for voided sleepers and cracks at the crossing nose. Furthermore, unlike conventional crossing nose, which required manual tamping, tamping car can be easily operated in the new design.

Furthermore, since the crossing nose and switch blades are no longer required, the manufacturing procedures are effectively simplified with the B2B switch design. Although an expansion joint needs to be specifically manufactured for the B2B switch, all the other interface components maintain the same rail profile.

Although there are a number of advantages of the present new switch design compared to the conventional S\&C, new problems arise. High impact occurs at the expansion joint and bending stiffness becomes weaker at this region and a more complex actuation and locking system is required. The aim of the work presented in this paper is to evaluate the proposed new S\&C concept, B2B switch, and investigates the required mechanism for the future. A preliminary design guidelines has proposed and the results from the new concept are compared to a conventional S\&C. Potential actuation mechanism and required locking position along the free rail are discussed. A 3D FE and MBS S\&C model has been developed for thermal and vehicle/turnout dynamics analysis to clarify the benefits of the proposed switch and to investigate potential better designs for the expansion joint. 


\section{Preliminary design}

This section includes an overview of the kinematic requirements for the B2B switch. Topics considered include: assessment of allowable stresses, required actuating movements, forces and locations, and the actuating mechanism. The railway track turnout of 760 m radius and 1:15 crossing angle turnout was considered as a baseline example. Two analysis zones have been identified, as shown in Figure 1. These require different design factors due to the turnout geometry. The required actuating mechanism, actuating movements $\left(d u_{y a}, d u_{y b}\right)$, locations $\left(L_{d 1}\right.$, $L_{d 2}$ ), and constrained locations $\left(L_{a}, L_{b}\right)$, for the whole turnout are investigated and the results from the B2B and conventional switches are compared. A more detailed schematic image of the B2B switch can be found in Figure 3.

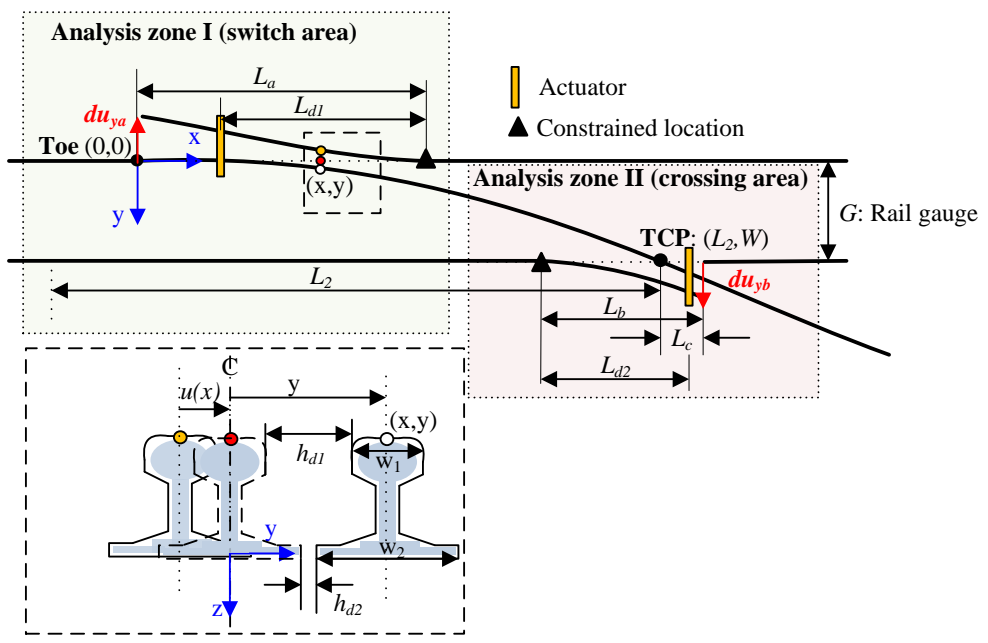

Figure 3. Schematic of lateral actuation movement for a turnout

\subsection{Maximum allowable stresses}

As the B2B switch bends one end of the rail transversally and vertically to match the main or diverging line, an assessment of the constrained location and maximum rail deformation based on stress limits needed to be investigated. An endurance stress was taken into account in order to allow an infinite service life for bending the rail in two directions. Endurance stress is usually considered to be $50 \%$ of the Ultimate Tensile Stress (UTS). Here, the endurance stress is assumed to be $450 \mathrm{MPa}$ based on UTS $900 \mathrm{MPa}$, which corresponds to a common steel grade used for a rail.

A 3D FE (UIC60) rail model was used to assess the maximum allowable stresses occurring when a load is applied at the end of a rail with different distance of constrained location from the free end and loading directions. The rail considered is assumed to be UIC 60,10 m long rail was used, and all degrees of freedom were constrained at the rail foot surfaces beyond the constrained location. The maximum Von Mises stresses from the model for the different scenarios are shown in Table 1 and Table 2 including vertical loading and transversal loading. Stress values that are larger than the endurance stress are emphasised in grey. The minimum distance between rail end and the constrained location can be identified from these tables (i.e. when the stress level is lower than the endurance stress). As might be expected, the results suggest that longer rail sections can withstand higher actuating movements.

In order to transfer a rail to its alternative position, the vertical and lateral displacements need to be greater than the rail height (172 $\mathrm{mm}$ for UIC60) and wider than the rail foot (150 $\mathrm{mm}$ for UIC60). Therefore, the constrained location needs to be at least $6 \mathrm{~m}$ from the free end in order to allow operation. However, larger actuating movements may be required to allow enough clearance for wheel flange passing and for two standard rail sections to be installed together. Therefore, the minimum constrained location may change slightly.

Table 1. Vertical displacement- maximum stresses for different constrain scenarios

\begin{tabular}{cllllllllll}
\hline \multirow{2}{*}{$\begin{array}{c}\text { constrained } \\
\text { location }\end{array}$} & 50 & 100 & $150 *$ & 200 & 250 & 300 & 350 & 400 & 450 & 500 \\
\hline $1 \mathrm{~m}$ & $2.3 \mathrm{Gpa}$ & $4.5 \mathrm{Gpa}$ & $6.8 \mathrm{Gpa}$ & $9.1 \mathrm{Gpa}$ & $11.3 \mathrm{Gpa}$ & $13.6 \mathrm{Gpa}$ & $15.8 \mathrm{Gpa}$ & $18.1 \mathrm{Gpa}$ & $20 \mathrm{Gpa}$ & $22.6 \mathrm{Gpa}$ \\
$2 \mathrm{~m}$ & $0.6 \mathrm{Gpa}$ & $1.2 \mathrm{Gpa}$ & $1.8 \mathrm{Gpa}$ & $2.4 \mathrm{Gpa}$ & $3 \mathrm{Gpa}$ & $3.3 \mathrm{Gpa}$ & $4.2 \mathrm{Gpa}$ & $4.8 \mathrm{Gpa}$ & $5.5 \mathrm{Gpa}$ & $6.1 \mathrm{Gpa}$ \\
$4 \mathrm{~m}$ & $0.17 \mathrm{Gpa}$ & $0.33 \mathrm{Gpa}$ & $0.51 \mathrm{Gpa}$ & $0.68 \mathrm{Gpa}$ & $0.85 \mathrm{Gpa}$ & $1 \mathrm{Gpa}$ & $1.2 \mathrm{Gpa}$ & $1.4 \mathrm{Gpa}$ & $1.5 \mathrm{Gpa}$ & $1.7 \mathrm{Gpa}$ \\
$6 \mathrm{~m}$ & $0.078 \mathrm{Gpa}$ & $0.16 \mathrm{Gpa}$ & $0.24 \mathrm{Gpa}$ & $0.31 \mathrm{Gpa}$ & $0.39 \mathrm{Gpa}$ & $0.47 \mathrm{Gpa}$ & $0.55 \mathrm{Gpa}$ & $0.63 \mathrm{Gpa}$ & $0.7 \mathrm{Gpa}$ & $0.79 \mathrm{Gpa}$ \\
$8 \mathrm{~m}$ & $0.044 \mathrm{Gpa}$ & $0.09 \mathrm{Gpa}$ & $0.13 \mathrm{Gpa}$ & $0.17 \mathrm{Gpa}$ & $0.22 \mathrm{Gpa}$ & $0.26 \mathrm{Gpa}$ & $0.3 \mathrm{Gpa}$ & $0.35 \mathrm{Gpa}$ & $0.39 \mathrm{Gpa}$ & $0.44 \mathrm{Gpa}$ \\
\hline
\end{tabular}


Table 2. Vertical displacement- maximum stresses for different constrain scenarios

\begin{tabular}{ccccccccccc}
\hline \multirow{2}{*}{$\begin{array}{c}\text { constrained } \\
\text { location }\end{array}$} & 50 & 100 & $150^{*}$ & $200^{*}$ & 250 & 300 & 350 & 400 & 450 & 500 \\
\hline $1 \mathrm{~m}$ & $1.7 \mathrm{Gpa}$ & $3.4 \mathrm{Gpa}$ & $5.1 \mathrm{Gpa}$ & $6.8 \mathrm{Gpa}$ & $8.6 \mathrm{Gpa}$ & $10 \mathrm{Gpa}$ & $12 \mathrm{Gpa}$ & $14 \mathrm{Gpa}$ & $15 \mathrm{Gpa}$ & $17 \mathrm{Gpa}$ \\
$2 \mathrm{~m}$ & $0.46 \mathrm{Gpa}$ & $0.92 \mathrm{Gpa}$ & $1.4 \mathrm{Gpa}$ & $1.8 \mathrm{Gpa}$ & $2.3 \mathrm{Gpa}$ & $2.7 \mathrm{Gpa}$ & $3.2 \mathrm{Gpa}$ & $3.7 \mathrm{Gpa}$ & $4.2 \mathrm{Gpa}$ & $4.6 \mathrm{Gpa}$ \\
$4 \mathrm{~m}$ & $0.12 \mathrm{Gpa}$ & $0.24 \mathrm{Gpa}$ & $0.36 \mathrm{Gpa}$ & $0.48 \mathrm{Gpa}$ & $0.6 \mathrm{Gpa}$ & $0.7 \mathrm{Gpa}$ & $0.8 \mathrm{Gpa}$ & $0.96 \mathrm{Gpa}$ & $1 \mathrm{Gpa}$ & $1.2 \mathrm{Gpa}$ \\
$6 \mathrm{~m}$ & $0.054 \mathrm{Gpa}$ & $0.11 \mathrm{Gpa}$ & $0.16 \mathrm{Gpa}$ & $0.22 \mathrm{Gpa}$ & $0.27 \mathrm{Gpa}$ & $0.32 \mathrm{Gpa}$ & $0.38 \mathrm{Gpa}$ & $0.43 \mathrm{Gpa}$ & $0.48 \mathrm{Gpa}$ & $0.53 \mathrm{Gpa}$ \\
$8 \mathrm{~m}$ & $0.038 \mathrm{Gpa}$ & $0.076 \mathrm{Gpa}$ & $0.11 \mathrm{Gpa}$ & $0.15 \mathrm{Gpa}$ & $0.19 \mathrm{Gpa}$ & $0.23 \mathrm{Gpa}$ & $0.26 \mathrm{Gpa}$ & $0.3 \mathrm{Gpa}$ & $0.34 \mathrm{Gpa}$ & $0.38 \mathrm{Gpa}$ \\
\hline
\end{tabular}

\subsection{Required actuation movements and forces}

The minimum required vertical movement for the B2B concept simply needs to be at least as high as the rail head to avoid collisions within the expansion joint (see Figure 2(b)). The required lateral movement is more complex. The two rail foots cannot overlap (i.e. one on top of the other), and at the same time they also have to provide enough clearance to allow the passage of a wheel flange. Different points of constraint require different lateral movements, e.g. a shorter distance to the constrained location requires more lateral movement to avoid overlapping of the rails. In this section, an algorithm is introduced to assess the lateral actuation movement and force with different constrained locations and points of actuation.

\subsubsection{Required minimum constrained location}

The minimum distances for the constrained locations for two analysis zones are calculated. As shown in Figure 1 and Figure 3, in order to avoid two rail sections overlapping each other for the B2B switch, the minimum free rail section $L_{a}, L_{b}$ need to be at least:

$$
\left\{\begin{array}{l}
L_{a} \geq \sqrt{r^{2}-\left(r-w_{2}\right)^{2}} \\
L_{b} \geq \sqrt{r^{2}-\left(G-r-w_{2}\right)^{2}}
\end{array}\right.
$$

where, $r$ is the radius of the turnout, $w_{2}$ is the width of the rail foot, and $G$ is the rail gauge. Furthermore, an additional length

$$
L_{c}=\frac{w_{2}}{2 \tan \left(0.5 \tan ^{-1}(\theta)\right)}
$$

is required beyond the theoretical crossing point (TCP) in order to have enough space for two rail feet, as shown in Figure 4.

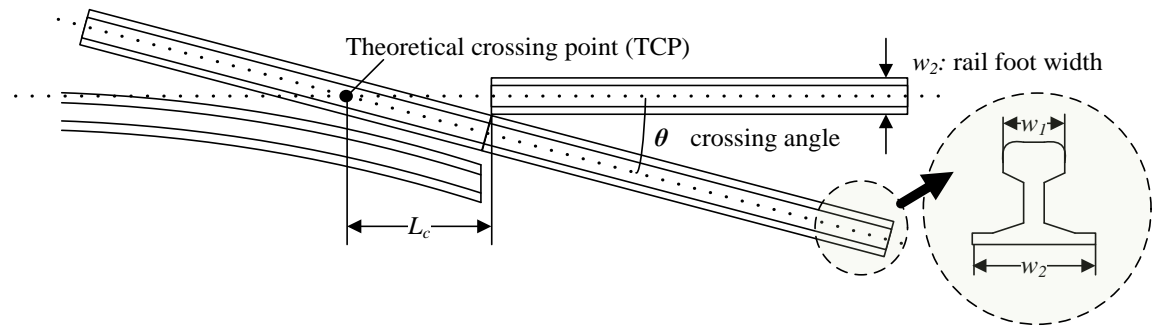

Figure 4. Schematic of required minimum distance beyond TCP in the crossing region

\subsubsection{Required lateral actuation movements and forces}

Although a minimum constrained location has been identified, a significant lateral actuation movement is required in order to avoid overlapping of the rails, especially in the region closest to the anchor (constrained) point. This can be reduced by increasing the length of the free rail or moving the actuator closer to the anchor point.

The clearance between the two rail heads, $h_{d 1}$, needs to be at least $35 \mathrm{~mm}$ to allow passage of a wheel flange. Additionally there needs to be a clearance between the two rail feet, $h_{d 2}$, in order for them not to overlap. When these criteria, as shown in Figure 3, are met, it is possible to calculate the minimum lateral movements required for a different constrained locations. A formula are shown in Eq. (3) for calculating the relative displacement along the two rail sections when a specific lateral displacement applied that match the above criteria.

$$
\left\{\begin{array}{l}
h_{d 1}(x)=a b s(y(x)-u(x))-w_{1} \geq 35 m m \\
h_{d 2}(x)=a b s(y(x)-u(x))-w_{2} \geq 0
\end{array}\right.
$$


where $y$ is the location of the curved rail (see Figure 3 ) and $w_{1}$ is the width of the rail head.

$$
y(x)=r-\sqrt{r^{2}-x^{2}}
$$

$u(x)$ is the transversal displacement of the bent rail along the whole turnout when a transversal load $P$ ' is applied.

$$
\begin{cases}u(x)=\frac{P^{\prime} x^{\prime 2}}{6 E I_{y}}\left(3 a^{\prime}-x^{\prime}\right) & 0<x^{\prime}<a^{\prime} \\ u(x)=\frac{P^{\prime} a^{\prime 2}}{6 E I_{y}}\left(3 x^{\prime}-a^{\prime}\right) & a^{\prime}<x^{\prime}<L^{\prime}\end{cases}
$$

where $E I_{y}$ is the rail transversal bending stiffness, $x^{\prime}$ is the distance from the constrained location, $a^{\prime}$ is the distance between the actuator and the constrained point, and $L^{\prime}$ is the length of the free rail. The corresponding values for two analysis zones are shown in Eq. (6).

$$
\text { Analysis zone I: }\left\{\begin{array} { l } 
{ P ^ { \prime } = - F } \\
{ x ^ { \prime } = ( L _ { a } - x ) } \\
{ a ^ { \prime } = L _ { d 1 } } \\
{ L ^ { \prime } = L _ { a } }
\end{array} \text { Analysis zone II: } \left\{\begin{array}{l}
P^{\prime}=F \\
x^{\prime}=\left(x-\left(L_{2}+L_{c}-L_{b}\right)\right) \\
a^{\prime}=L_{d 2} \\
L^{\prime}=L_{b}
\end{array}\right.\right.
$$

where $L_{2}$ is the length between the switch toe and the TCP, and $F$ is the required lateral actuating force at the point of actuation with the given lateral displacements, $d u_{y}$, at the free end.

A design algorithm is introduced, as shown in Figure 5, based on above procedure to calculate the required lateral movements and forces for specific constrained and actuating locations. Where $L_{i}$ is the $i$ attempt for calculating the required free rail length and $\Delta L$ is the increment for each attempt.

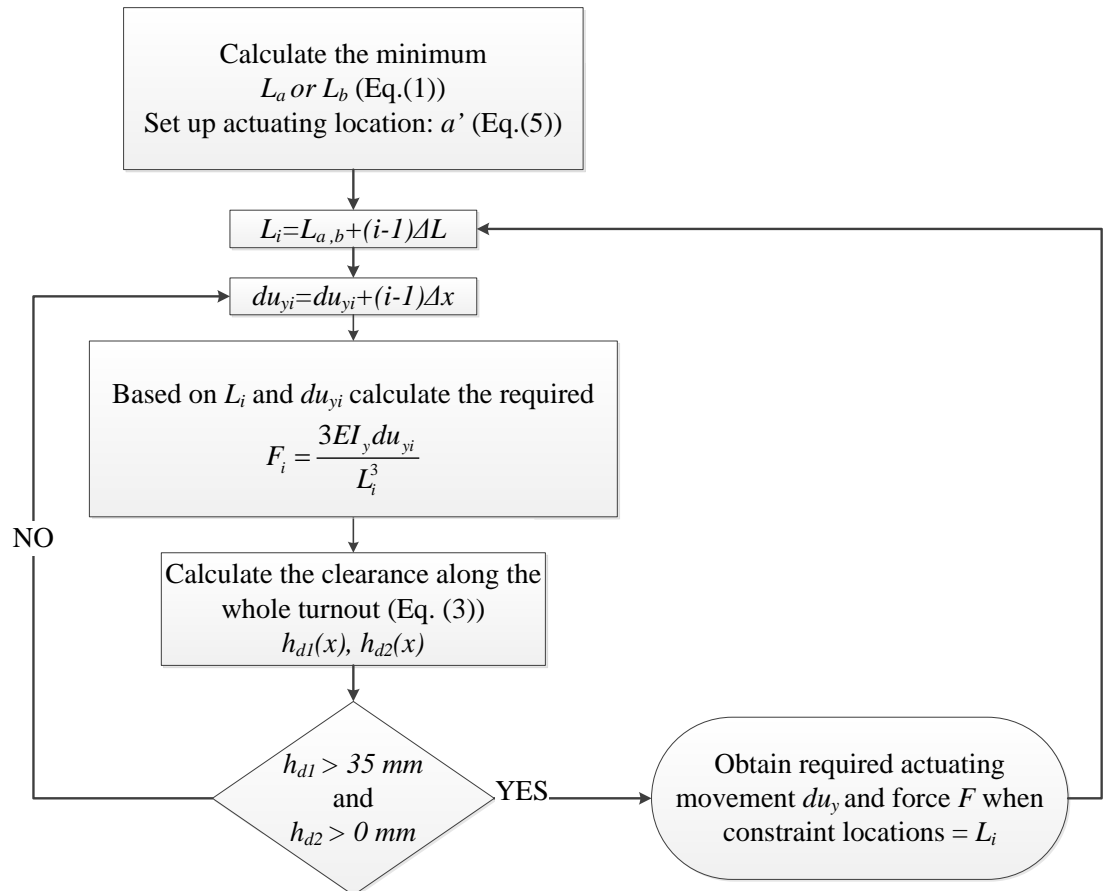

Figure 5. Flow chart for calculating the required lateral actuating movements and forces for different constrained locations

The required lateral displacements at the free rail end, and the required actuating forces, for different constrained and actuating locations in two analysis zones are shown in Figure 6. The results are based on the $760 \mathrm{~m}$ radius and 1:15 crossing angle turnout. Three different actuation locations are considered: at the end, half, and one third of the free rail section length. As shown, a shorter free rail section requires greater lateral displacement, and the required free rail length decreases when the actuating force is further from the free end. However, the required actuating force increases in this case. 
Based on the results presented in Figure 6, the required lengths of the free rails, $L_{a}, L_{b}$, can be identified to support the desirable (design) lateral actuation movements. The minimum required lateral actuation movements, $d u_{y a}, d u_{y b}$, for analysis zone I and zone II are $200 \mathrm{~mm}$ and $350 \mathrm{~mm}$, respectively. However, a larger actuation movement may be required for zone I in order to decrease the required length of the free rail section.

For analysis zone I, although placing the actuator further from the free end can reduce the required length of the free rail, only a reduction of $0.5 \mathrm{~m}$ is achieved. Furthermore, a higher actuation force is required when applying the force further from the free end. Therefore, the constrained location for zone I needs to be at least $17 \mathrm{~m}$ from the free end to allow a reasonable actuation movement.

Despite a $6 \mathrm{~m}$ long free rail being enough to provide the required lateral movement of $550 \mathrm{~mm}$ for analysis zone II, the stress level observed in this configuration is higher than the endurance stress, which may result in fatigue failure. Furthermore, in order to obtain a reasonable actuation force, lower than $2 \mathrm{kN}$, the actuation location is suggested to be at the free end. Therefore, the constrained location is suggested to be at least $8 \mathrm{~m}$ from the free end.
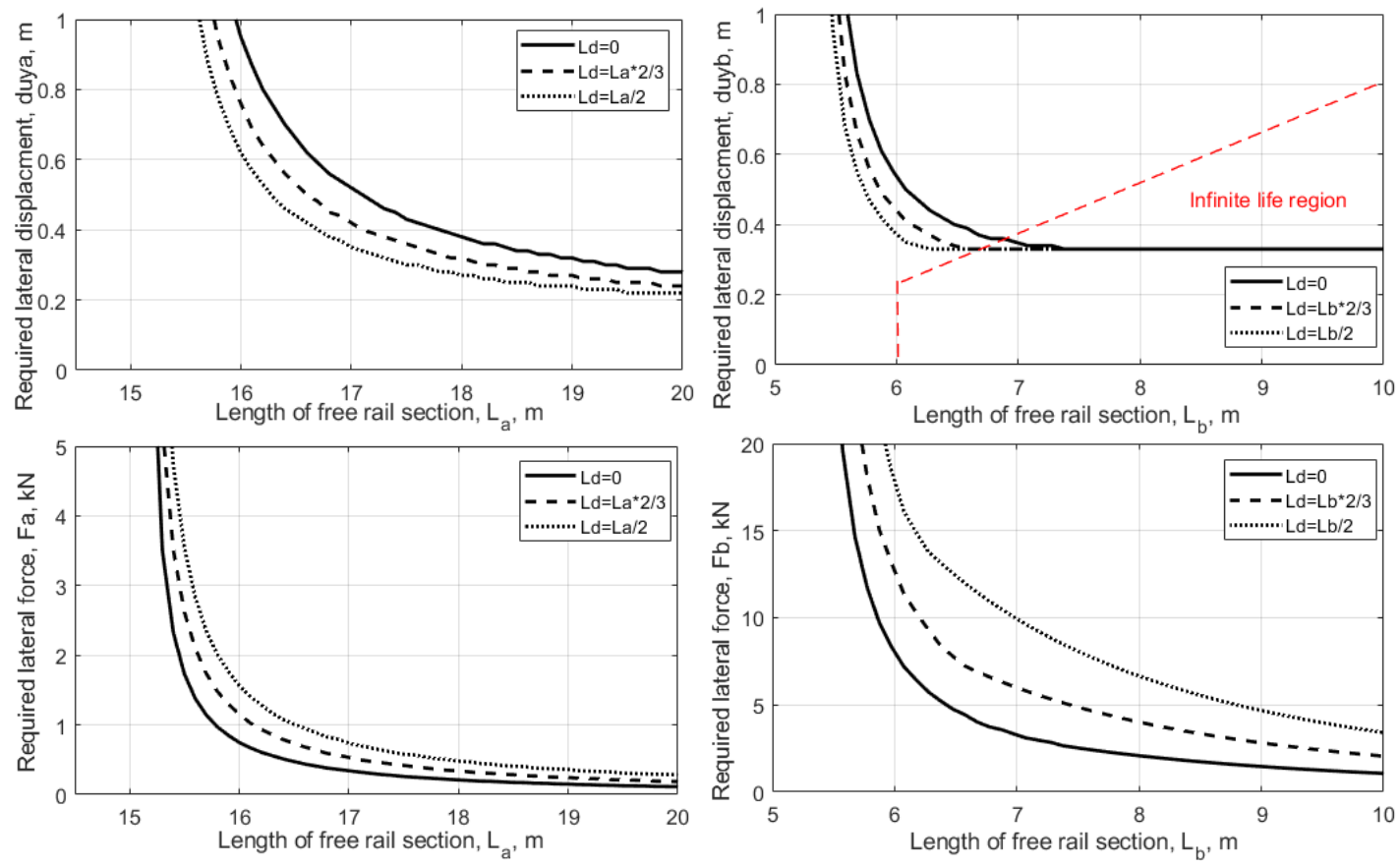

(a)

(b)

Figure 6. Required lateral actuation movements and forces for two analysis zones; (a) analysis zone I; (b) analysis zone II

\subsection{Investigation of the potential actuating and locking mechanism}

\subsubsection{Actuating}

When the switch is in a transient state, it is necessary to ensure that the moving rail does not catch the adjacent fixed rail. Figure 7 shows the crossing region of a switch in the transient state. In the figure, the moving rail is lifted over a fixed rail to mate with its counterpart. In the B2B concept, a conventional expansion joint design was incorporated and so, the actuation mechanisms must be designed accordingly. As shown in Figure 7, the arrangement of the expansion joints suggests that the trajectory for the switch rail movement needs to be of a noncircular fashion. Figure 7(a) and (b) show the potential trajectories for analysis zone I and II.

This trajectory can be achieved using carefully designed four bar linkage mechanisms or a two-actuator arrangement such that the switch tip can be slid across an arm which in turn is rotated about one of its end (close to the ground) to provide translation in the curved surface swept by the arm. Another possibility is to use twoactuator combination implemented such that each linear actuator can provide a degree of freedom (DoF) in each linear axis. These two-actuator arrangement approaches allow self-adjustment of the switch to correct any misalignment. However, it is possible that it may lose its bistability function. Using one actuator in conjunction with four bar linkage mechanism would retain the bistable nature of the switch. The joints at the actuator links need to be spherical to allow the switch rail to move freely when bent in both the vertical and horizontal planes. Alternatively, compliant joints such as those used in stretcher bars can be used. 

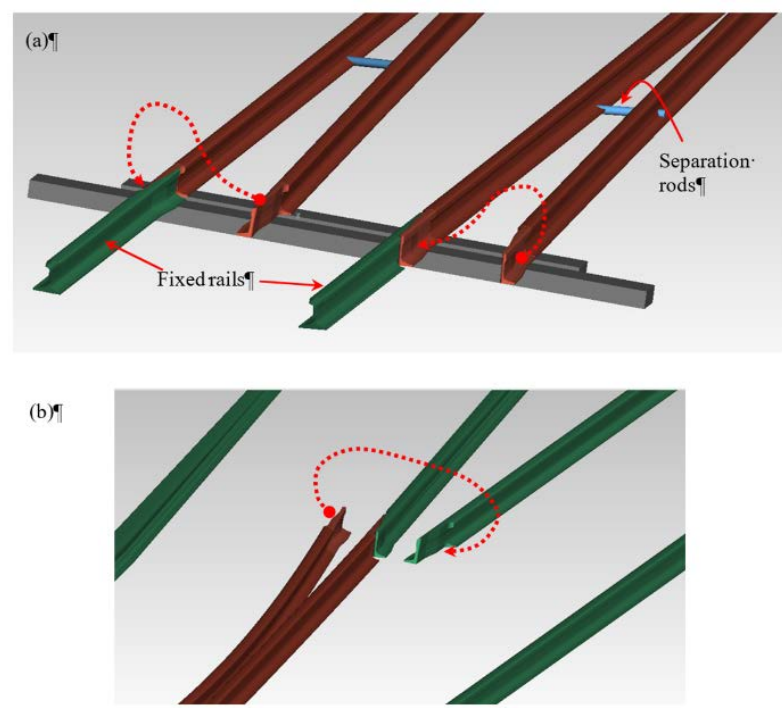

Figure 7. Proposed trajectories for the B2B switch concept (red dotted curves) with a conventional expansion joint at (a) analysis zone I and (b) analysis zone II

\subsubsection{Locking}

Locking at the switch end is no longer required. The new design provides passive locking mechanism using rail gravity. However, a number of locking positions are required in order to hold the free rails. Some possible locking mechanism such as locking using magnets or electromagnets are introduced in [19]. It is eventually suggested to lock every sleepers along the free rail in order to provide sufficient longitudinal and lateral resistance. Furthermore, in order to eliminate the gap within expansion joint to reduce the impact forces, it is also suggested to lock every sleeper along the free rail in analysis zone II and minimum $80 \%$ of free rail in analysis zone I based on the thermal analysis.

\section{Design evaluation}

Design of expansion joint is one of the crucial component for the proposed new concept. It is important to evaluate the influence of thermal and wheel/rail contact forces at expansion joints in order to provide a better design guideline and to justify the benefit compared to the conventional S\&C.

\subsection{Thermal effect}

Thermal analysis is introducing here using 3D FE switch model for the conventional S\&C and B2B switches, as shown in Figure 8. For the conventional S\&C, beam elements with variations of moment of inertia and cross sectional area are used to represent the switch blades, crossing nose, and check rail. For the B2B switch, standard UIC60 rails, are used for the whole turnout in which there are three expansion joints. Flexibility of sleepers is considered by using beam elements with multiple spring-dashpots below the sleepers as foundations, and a springdashpot for each railpad connected between the rail and the sleeper. Parameters for each component can be found in Table 3.

A 1/5 scale single-sleeper pull-out test was carried out by Koike et al. [20] to investigate the resistance between a sleeper and the ballast. In the test a $1 \mathrm{~mm}$ lateral displacement of the sleeper was obtained with $0.08 \mathrm{kN}$ of lateral force. A factor of 125 needs to be applied in order to determine the correct lateral resistance at full scale [20]. Therefore, the lateral resistance between sleeper and ballast for the model presented is $10 \mathrm{kN}$. The longitudinal resistance between a sleeper and the ballast is usually lower than the resistance between rail and fastener and is difficult to control due to the fact that the resistance depends on the geometry of the sleeper and the ballast, the weight of the sleeper, and the ballast compaction and ballast particle size. In this work, the longitudinal sleeper/ballast resistance is assumed to be the same as the lateral resistance.

The same turnout type introduced in section 3 is used here for the thermal analysis. All degrees of freedom are constrained at the end of the rail beam except the switch rails. Temperature variation is set to be $26.7^{\circ}$. A number of locking positions along the free rail of the B2B switch are considered to identify the required locking position in terms of thermal effect. The same parameters as those for the fastener system are used for each locking position to account for the locking mechanism. In the analysis, different number of locking positions are considered along the free rail, starting from one at the first sleeper at the free end till every sleeper. Here the maximum locking position for Analysis zone I and II are 27 and 10, respectively. 
Here the left and right rail is based on the straight and diverging direction. For conventional S\&C, the longitudinal relative displacements between the left switch and stock rail and the right switch rail and stock rail are $10.9 \mathrm{~mm}$ and $11.6 \mathrm{~mm}$, respectively. Switch rail is manufactured specifically to match stock rail in order to provide a smooth contact profile and to guide a wheel through a switch. Any additional displacements may result in poorer wheel/rail contact mechanism.

Relative displacements within the expansion joint from a B2B switch, between the left and right rail in the switch region (Analysis zone I) and the crossing region (Analysis II), are shown in Figure 9. Relative displacements in the switch region are larger than those in the crossing region, with values of around 15-20 mm and 4.5-5.5 mm, respectively. With more locking positions (constrained points) along the free rail section, the relative displacement tend to decrease for both regions. However, when every sleeper are locked in analysis zone II, the relative displacements within this region tend to increase when more locking position applied in the analysis zone I.

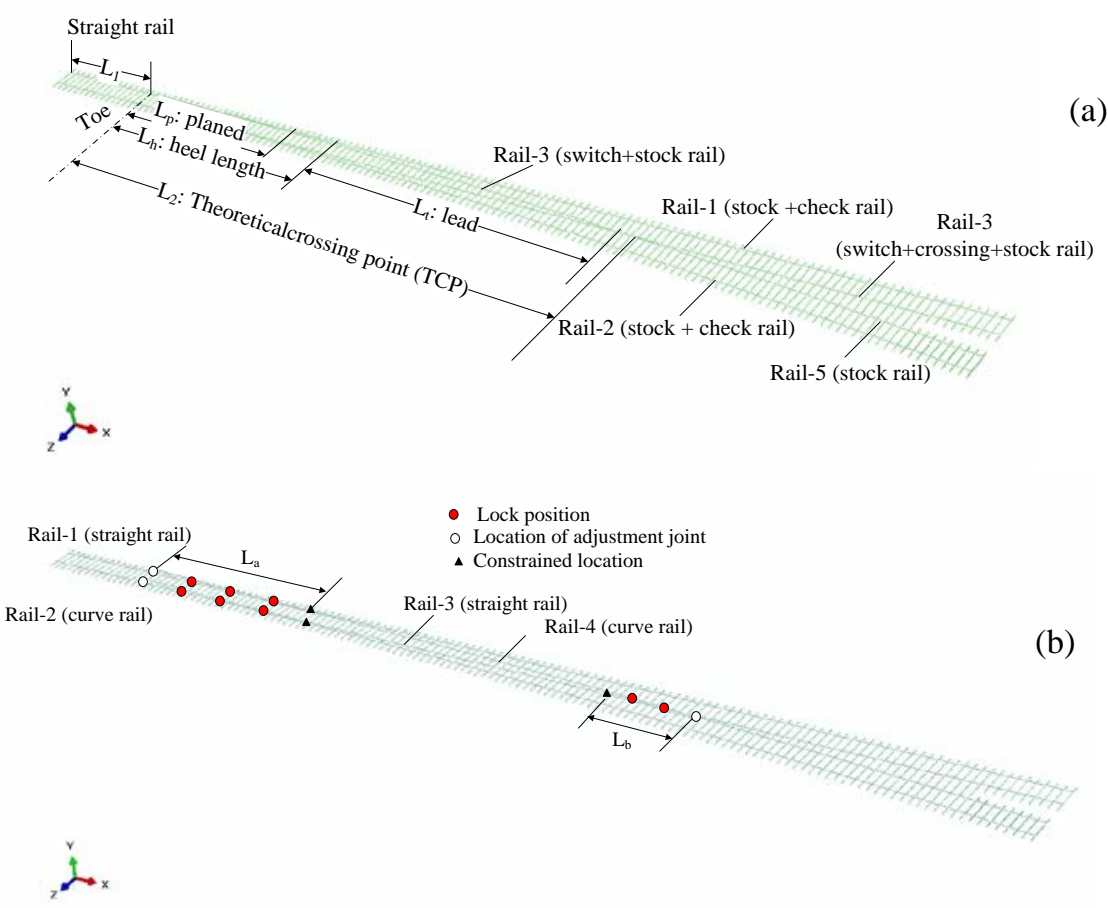

(a)

Figure 8. 3D FE model; (a) conventional S\&C; (b) B2B switch

Table 3. Parameters for substructure

\begin{tabular}{ll}
\hline Railpad longitudinal resistance , $\mathrm{K}_{\mathrm{px}}$ & $15 \mathrm{kN}$ for $1 \mathrm{~mm}$ [21] \\
Railpad stiffness in the transversal direction, $\mathrm{K}_{\mathrm{pz}}$ & $500 \mathrm{MN} / \mathrm{m}$ \\
Railpad stiffness in the vertical direction, $\mathrm{K}_{\mathrm{py}}$ & $300 \mathrm{MN} / \mathrm{m}$ (calibrated based on [22]) \\
Sleeper/ballast longitudinal resistance, $\mathrm{K}_{\mathrm{fx}}$ & $10 \mathrm{kN}$ for $1 \mathrm{~mm}$ \\
Sleeper/ballast lateral resistance, $\mathrm{K}_{\mathrm{fz}}$ & $10 \mathrm{kN}$ for $1 \mathrm{~mm}$ [20] \\
Foundation stiffness in the vertical direction, $\mathrm{K}_{\mathrm{fy}}$ & $40 \mathrm{MN} / \mathrm{m}^{2}$ (calibrated based on [22]) \\
\hline
\end{tabular}
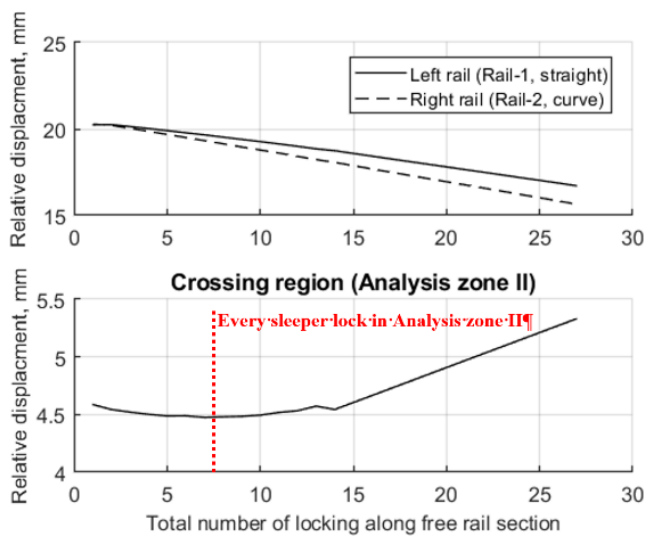

Figure 9. Two rail relative displacements at the expansion joint with different number of locking along the free rail 
Although the gap for the standard expansion joint design is $100 \mathrm{~mm}$, a smaller gap can be considered for the B2B switch design, which can reduce the wheel/rail contact force (see Section 5.3). Based on this study, minimum gaps of $20 \mathrm{~mm}$ and $5.3 \mathrm{~mm}$ are required for the B2B switch in Analysis zone I and II, respectively. The minimum relative displacements in the switch region are around $16.7 \mathrm{~mm}$ for the left rail and $15.6 \mathrm{~mm}$ for the right rail, which are larger than those for the conventional switch. However, the design of the expansion joint provides better alignment compared to the mismatch in switch and stock profiles of the conventional switch in the longitudinal direction. In the end, although required locking position can be low, it is not recommended to be lower than 20 ( $80 \%$ of the total length) for analysis zone I positions due to a need to obtain larger longitudinal resistance to account for wheel/rail friction.

\subsection{Vehicle / turnout interaction dynamics}

\subsubsection{Model development}

A multi-body simulation model for examining the new switch and crossing concept was developed in Simpack using its rail environment. On the track level, the geometry of the turnout and parameters of the rail foundation were modelled. The second part of simulation model is a complete vehicle which contains Y25 bogies and has an axle load of $25 \mathrm{t}$. Each of these models are described below and make use of the parameters detailed in [23].

A model of a railway track turnout of $760 \mathrm{~m}$ radius and 1:15 crossing angle, as defined by European standards, was developed. The rail foundation was implemented as a spring-mass-damper system with two masses. The mass of rail along with stiffness and damping of the railpads constitute one subsystem, and the lumped mass of the ballast along with its stiffness and damping comprise the second subsystem. This two mass system has three degrees of freedom with displacements in the vertical and lateral directions, in addition to roll around the longitudinal axis. The parameters of the individual components are listed in [22].

The vehicle comprises of two Y25 bogies which are attached by a centre bowl to the body of the vehicle. The basic parameters of the suspension components, along with the bogie mass and inertial components, are taken from [23]. The axle load is set to be $25 \mathrm{t}$. In a Y25 bogie, the primary suspension consists of friction wedges, which act as dampers, and tare and laden springs which provide stiffness. Apart from these, a Lenoir link is present to provide coupling between the longitudinal and vertical spring forces. The longitudinal forces in this link affect the friction wedges. In simulation, a simplified model of this Lenoir link and its associated force components is assumed.

The ends of the switch rails were designed to have expansion joints as shown in Figure 2. The design of the expansion joint was adapted from an existing UK switch, owned and managed by network rail (Drawing no. 113/A/00/15/300). In Figure 10, the left panel shows the plan view, and the two insets on the right show crosssections of the rail head at the locations indicated by the arrows. The Simpack software requires a cross section of the rail head to be defined in order to model the rail-wheel contact. A MATLAB script was written to generate multiple cross sections and to load them into the Simpack software.

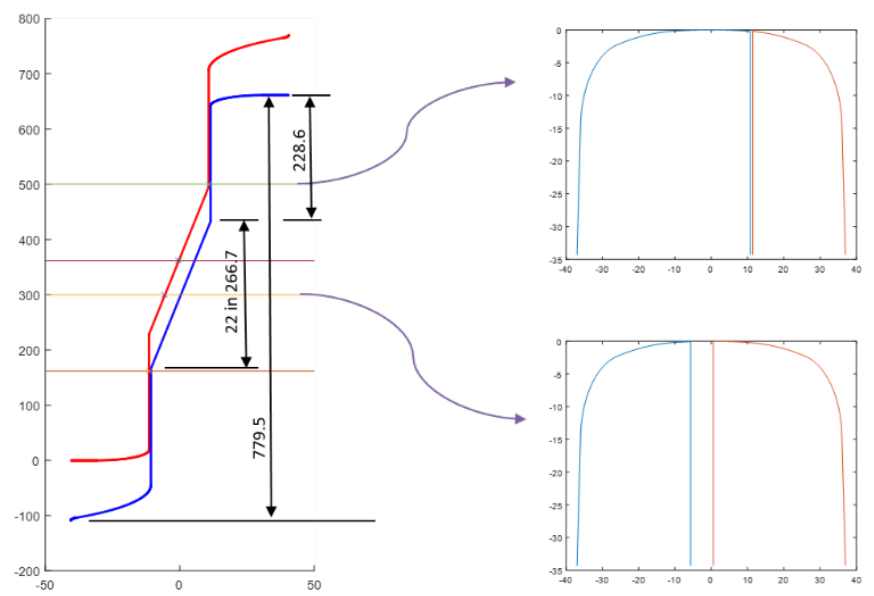

Figure 10. Rail profiles for the expansion joint used in the B2B switch (Dimensions are in mm).

\subsubsection{Model validation}

The combined vehicle and track model has been validated against real wheel-rail contact forces measurement. In the model, a freight with Y25 bogie was run at $80 \mathrm{~km} / \mathrm{hr}$ through a $760 \mathrm{~m}$ radius and 1:15 crossing angle turnout in the diverging direction and the vertical and lateral contact forces at the right and left wheels of the leading wheelset of the leading bogie were recorded. The results were recorded at $200 \mathrm{~Hz}$ to match the sampling rate of the real data. The results of both the simulation and the measurements are shown in Figure 11. The plots show the 
forces against the location of the leading wheelset, measured from the front of the turnout. There is a reasonable agreement between the model and the real measurements, especially in the low frequency amplitudes and peak levels. The flange contact in the case of the simulated wheel occurs earlier than for the measured wheel, which is observed in the lateral contact forces about $3 \mathrm{~m}$ from the front of the turnout. In the region $15-20 \mathrm{~m}$ from the front of turnout there the simulation reports higher lateral forces on both the left wheels. These are due to modelling a simplified primary suspension. Moreover, the variation in track gauge as reported in [22] was not included in the simulation. The vertical and lateral forces both agree well with the measured data at the crossing nose, which is approximately at $47 \mathrm{~m}$ from front of the turnout. This provides confidence that the model is appropriate for evaluation purpose, which is to predict the performance of the B2B switch layout, relative to that of a conventional switch.

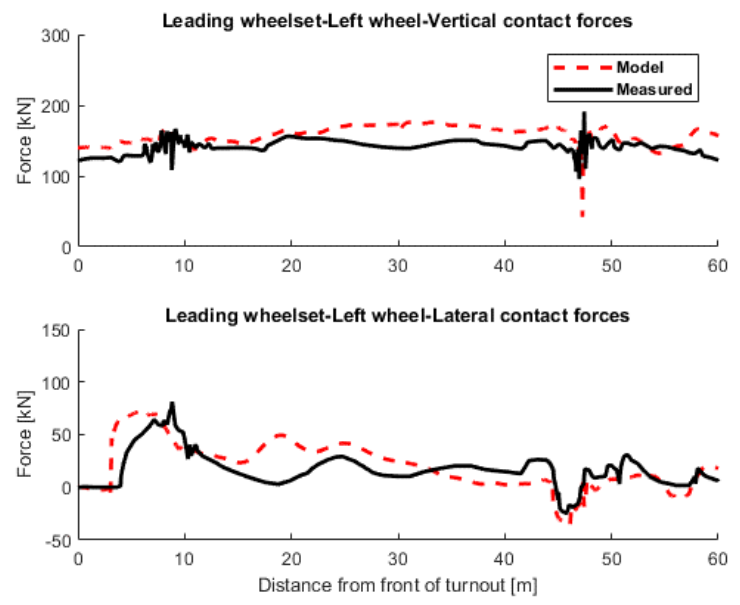

Figure 11. Validation of contact forces on the outer wheel

\subsubsection{Numerical results}

The vehicle model validated above has also been run on the same turnout but equipped with the B2B switch. From the perspective of wheel-rail interaction, the expansion joint is the main component which is different from the conventional S\&C. The expansion joint has a normal gap of $100 \mathrm{~mm}$, but for purposes of comparison smaller and larger gaps of $25 \mathrm{~mm}$ and $150 \mathrm{~mm}$ have been considered. The vehicle is run with the same test conditions as used above, and the contact forces obtained in the three cases are compared against the signals obtained for the conventional S\&C in Figure 12(a). In this figure the switch toe is positioned at $0 \mathrm{~m}$ and crossing nose is at $45.7 \mathrm{~m}$.

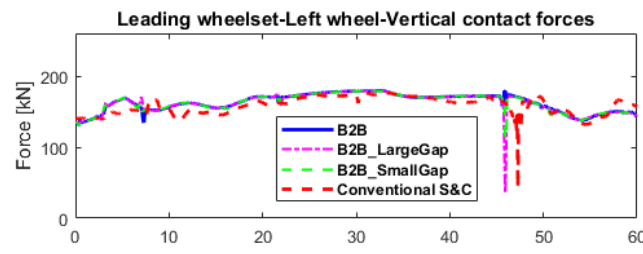

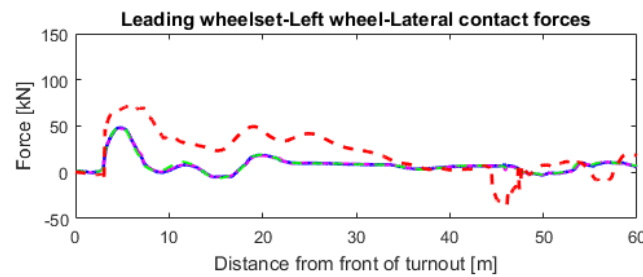

(a)

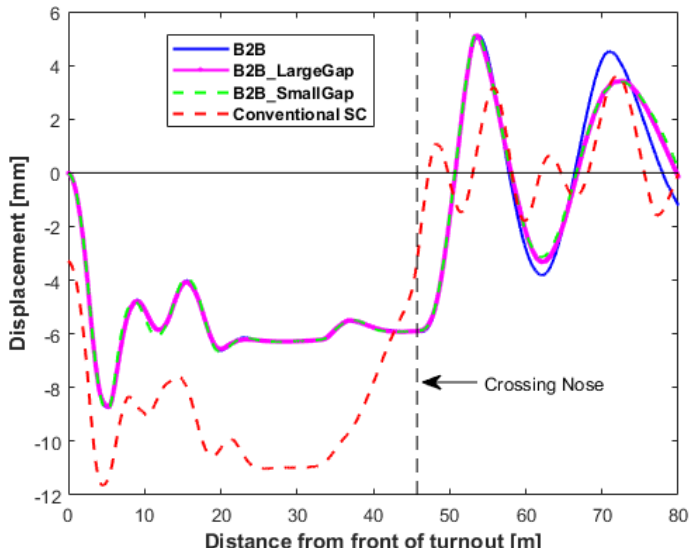

(b)

Figure 12. B2B concept simulations with three different gaps in the expansion joint; (a) contact forces; (b) wheelset lateral displacement

The peak deviation of vertical contact forces from the static wheel load is presented in Table 4 . It can be observed that there are no differences between all the compared cases in the switch region, as there is no loss of contact area between the wheel and rail. However at the crossing section there is a significant drop in contact forces. The drop of forces at this region in conventional S\&C is due to the gap in front of the crossing nose. In the B2B S\&C concept, the drop is due to sudden loss of contact area because of the gap in joint. As expected, the joint with large gap shows a larger drop. Another point to be noted is the different behaviour of the contact forces in 
B2B S\&C concept at switch and crossing regions. Though the joint and the gaps would be the same in each case, the drop of forces in crossing region is significant compared to the switch region. This can be reasoned due to the layout of the turnout along with the wheelset lateral displacement as shown in Figure 12(b). The layout at the switch section is a straight-curve transition and at crossing region it is a straight-straight transition. The B2B joint at the switch region is encountered at $0 \mathrm{~m}$ where the wheelset is at the middle of the track. When the same joint is encountered by the wheelset at crossing region, it is laterally displaced by $6 \mathrm{~mm}$ towards the outside of the curve, and hence the left wheel passes through the gap at a larger radii, whereas the right wheel passes through a continuous rail. This asymmetry causes larger vertical force drop at the crossing region for the B2B S\&C concept.

It is shown that the predicted lateral contact forces are considerably reduced in both the switch and crossing regions of B2B S\&C concept compared to the conventional S\&C, as shown in Figure 12 and Table 4. However the gaps in the individual B2B cases did not affect the lateral forces.

Table 4. Comparison of peak value to conventional S\&C

\begin{tabular}{ccc}
\hline & At switch region & At crossing region \\
\hline Peak deviation of vertical contact force from static load & & \\
Conventional S\&C & $34.5 \mathrm{kN}$ & $52.5 \mathrm{kN}$ \\
B2B & $34.5 \mathrm{kN}$ & $45 \mathrm{kN}$ \\
B2B_LargeGap & $35 \mathrm{kN}$ & $100 \mathrm{kN}$ \\
B2B_SmallGap & $34.5 \mathrm{kN}$ & $21.5 \mathrm{kN}$ \\
\hline Peak values of lateral contact forces & & $-37 \mathrm{kN}$ \\
Conventional S\&C & $89.48 \mathrm{kN}$ & $-5 \mathrm{kN}$ \\
B2B & $49.36 \mathrm{kN}$ & $-0.75 \mathrm{kN}$ \\
B2B_LargeGap & $49.36 \mathrm{kN}$ & $-0.5 \mathrm{kN}$ \\
B2B_SmallGap & $49.36 \mathrm{kN}$ & \\
\hline
\end{tabular}

\section{Conclusions}

A new concept, the B2B switch, has been proposed. The design requirements have been evaluated and a method for assessing actuation movements and constrained locations has been developed and applied to the radius $760 \mathrm{~m}$ with 1 in 15 turnout. In this example, lateral actuation movements of $500 \mathrm{~mm}$ and $350 \mathrm{~mm}$, and anchor points of $17 \mathrm{~m}$ and $8 \mathrm{~m}$, have been identified for analysis zones I and II respectively. These values have been selected in order to provide sufficient clearances and to avoid fatigue through bending actions. A possible actuation mechanism has been introduced in which two actuators are used to provide a non-circular trajectory.

An adjustable expansion joint has been considered as part of the concept and minimum gaps of around $20 \mathrm{~mm}$ for analysis zone I and $5.5 \mathrm{~mm}$ for analysis zone II have been demonstrated to be sufficient to compensate for thermal expansion effects. Furthermore, regarding the required number of locking position for the moveable rail, the longitudinal displacement can be minimised and lateral and longitudinal forces can be provided more effectively.by locking every sleeper in Analysis zone II, and using a minimum $80 \%$ of total free length in Analysis zone I.

Wheel/rail contact forces have been shown to be significantly reduced with the new design. The lateral forces are improved by around $45 \%$ and $86 \%$ in the switch and crossing regions respectively when the stander expansion joint is used. More reduction can be achieved when a smaller gap design is used. Although the vertical contact forces from B2B concept maintain the same compared to the conventional S\&C, around 14\% contact force reduction is found and more improvement can again be achieved when smaller gap design is used.

The new concept has shown high potential to increase service life due to less wheel/rail impact forces and more uniform track stiffness. Furthermore, maintenance approach (e.g. tamping car), manufacture, and assembly procedure can be more efficient comparing to the conventional S\&C. However, larger actuation forces and a more complex actuating mechanism are required for the B2B switch compared to a conventional switch. It is also challenging to provide both longitudinal and lateral resistance for such a long free rail. A further research is required in order to give a more complete design.

\section{Acknowledgement}

The work described has been supported by the S-CODE project. This project has received funding from the Shift2Rail Joint Undertaking under the European Union's Horizon 2020 research and innovation programme under grant agreement No 730849. This publication reflects only the authors' view and the Shift2Rail Joint Undertaking is not responsible for any use that may be made of the information it contains. The authors also would like to 
acknowledge Dr. Björn Pålsson from Chalmers University and Trafikverket for sharing rail profiles and measurement data.

\section{References}

[1] Nissen A, Colina J, Eiby JU, Taymans M, Lundgreen SO KC. Inspection of switches \& crossings. State of the Art Report. 2011.

[2] Rusu MF. Automation of railway switch and crossing inspection. University of Birmingham; 2015.

[3] Lagos RF, Alonso A, Vinolas J, et al. Rail vehicle passing through a turnout: analysis of different turnout designs and wheel profiles. Proc. Inst. Mech. Eng. Part F J. Rail Rapid Transit. 2012;226:587-602.

[4] Pålsson BA, Nielsen JCO. Wheel-rail interaction and damage in switches and crossings. Veh. Syst. Dyn. 2012;50:43-58.

[5] Bezin Y, Grossoni I, Neves S. Impact of wheel shape on the vertical damage of cast crossing panels in turnouts. Dyn. Veh. Roads Tracks, Proc. 24th Symp. Int. Assoc. Veh. Syst. Dyn. (IAVSD 2015). 2015. p. 17-25.

[6] Kassa E, Andersson C, Nielsen JCO. Simulation of dynamic interaction between train and railway turnout. Veh. Syst. Dyn. 2006;44:247-258.

[7] Shih J-Y, Kostovasilis D, Bezin Y, et al. Modelling options for ballast track dynamics. 24th Int. Congr. Sound Vib. ICSV 2017. 2017.

[8] Kassa E, Nielsen JCO. Stochastic analysis of dynamic interaction between train and railway turnout. Veh. Syst. Dyn. 2008;46:429-449.

[9] Wan C, Markine VL, Shevtsov IY. Analysis of train/turnout vertical interaction using a fast numerical model and validation of that model. Proc. Inst. Mech. Eng. Part F J. Rail Rapid Transit. 2014;228:730-743.

[10] Johansson A, Pålsson B, Ekh M, et al. Simulation of wheel-rail contact and damage in switches \& crossings. Wear. 2011;271:472-481.

[11] Xin L, Markine VL, Shevtsovb IY. Numerical procedure for fatigue life prediction for railway turnout crossings using explicit finite element approach. Wear. 2016;366-367:167-179.

[12] Siew JS, Mirza O, Kaewunruen S. Nonlinear finite element modelling of railway turnout system considering bearer / sleeper-ballast interaction. Journal of Structures. 2015;2015.

[13] Pålsson BA, Nielsen JCO. Track gauge optimisation of railway switches using a genetic algorithm. Veh. Syst. Dyn. 2012;50:365-387.

[14] Nicklisch D, Kassa E, Nielsen J, et al. Geometry and stiffness optimization for switches and crossings, and simulation of material degradation. Proc. Inst. Mech. Eng. Part F-Journal Rail Rapid Transit. 2010;224:279292.

[15] Wang P, Ma X, Wang J, et al. Optimization of rail profiles to improve vehicle running stability in switch panel of high-speed railway turnouts. Math. Probl. Eng. 2017;2017:1-13.

[16] Shih J-Y, Hemida H, Stewart E, Robert C. Understand the impact of train run-throughs on railway switches using Finite Element Analysis. Proc. Inst. Mech. Eng. Part F-Journal Rail Rapid Transit. 2018;233(4): 359369.

[17] Bemment SD, Ebinger E, Goodall RM, et al. Rethinking rail track switches for fault tolerance and enhanced performance. Proc. Inst. Mech. Eng. Part F J. Rail Rapid Transit. 2017;231:1048-1065.

[18] Winterproof turnout. http://www.winterproofturnout.info/

[19] Project Switch and Crossing Optimal Design and Evaluation deliverable. D5.1 Next-generation kinematic systems: actuators and mechatronics. http://www.s-code.info/media/1102/d5-1-next-generation-kinematicsystems-actuators-and-mechatronics.pdf.

[20] Koike Y, Nakamura T, Hayano K, et al. Numerical method for evaluating the lateral resistance of sleepers in ballasted tracks. Soils Found. 2014;54:502-514.

[21] BS EN 13146-1:2002 Railway Applications. Track. Test Methods For Fastening Systems. Determination of Longitudinal Rail Restraint (British Standard).

[22] Kassa E, Nielsen JCO. Dynamic interaction between train and railway turnout: Full-scale field test and validation of simulation models. Veh. Syst. Dyn. 2008;46:521-534.

[23] Braghin F, Ekberg A, Pålsson B, Sala D, Nicklisch D, Kabo E, Braghin F, Allen P, Shackleton P, Vernersson T, Pineau M. Analysis and mitigation of derailment, assessment and commercial impact (D3.2). Development of the Future Rail Freight System to Reduce the Occurrences and Impact of Derailment. 2013.

(C) 2020 by the author(s). This work is licensed under a Creative Commons Attribution 4.0 International License (http://creativecommons.org/licenses/by/4.0/). Authors retain copyright of their work, with first publication rights granted to Tech Reviews Ltd. 